\title{
Turismo e Representações na Ilha de Itamaracá: o espaço vivido em foco ${ }^{1}$
}

\author{
Tourism and Representations in Itamaracá Island: \\ the lived space in focus
}

Lenilton Francisco de Assis ${ }^{2}$

RESUMO: Este artigo analisa as mudanças engendradas pelo turismo na Ilha de Itamaracá-PE, onde o crescimento das segundas residências tem modificado o meio ambiente e incidido nas representaçōes do espaço vivido dos "nativos".

PALAVRAS-CHAVE: turismo e espaço; crescimento de segundas residências; impactos; representaçōes; Ilha de Itamaracá; Pernambuco; Brasil.

ABSTRACT: This article analyses the changes engendered by the tourism in Itamaracá Island (PE), where the increase of second homes has been modifying the environment and influenced the representations of the lived space of the "native ones".

KEYWORDS: tourism and space; increase of second homes; impacts; representations; Itamaracá Island; Pernambuco; Brazil.

1. Texto adaptado da dissertação defendida pelo autor (Assis, 2001) no Mestrado em Geografia da UFPE, sob a orientação da Prof ${ }^{2}$. Dra ${ }^{a}$. Edvânia Torres Aguiar Gomes.

2. Mestre em Geografia pela Universidade Federal de Pernambuco. Professor Assistente do Curso de Geografia da Universidade Estadual Vale do Acaraú (UVA-CE). E-mail: lenilton@yahoo.com 


\section{Introdução}

As ilhas são arquétipos do imaginário coletivo humano que evocam diversas representações e remetem a idéias de aventuras, paraísos, prisões e até riscos. A peculiaridade geográfica de serem porções de terra menores que os continentes e cercadas de água por todos os lados confere às ilhas status de um mundo exótico, diferente de qualquer lugar.

As ilhas tropicais e subtropicais exercem um peculiar fascínio às representações dos continentais, integrando as principais rotas do turismo internacional, modelo SSSS: sea, sand, sun and sex-mar, areia, sol e sexo.

Em muitos casos, o turismo intensifica a urbanização das ilhas tropicais, transformando-as, principalmente, em balneários de veraneio. Por outro lado, esse processo também resulta em modificações na paisagem natural, assim como nos gêneros de vida e no espaço vivido da população "nativa" ", que cada vez mais expropriada do espaço, confere às representações o sentido de uma dimensão e de uma relação perdidas. Vale ressaltar que, neste trabalho, consideram-se representações na perspectiva de Moscovici (1978), ou seja, representação social como "um corpus organizado de conhecimentos e uma das atividades psíquicas graças às quais os homens tornam inteligível a realidade física e social, inserem-se num grupo ou numa ligação cotidiana de trocas, e liberam os poderes de sua imaginação”. Assim, a representação social corresponde ao conhecimento particular, às imagens, idéias e valores construídos pelos indivíduos na vida coletiva que lhes permitem se comunicar, "interpretar e reinterpretar" o espaço em que vivem.

Sendo assim, este artigo objetiva analisar, por meio das representações do espaço vivido, as mudanças acarretadas pelo turismo na Ilha de Itamaracá-PE. Para tanto, ele está dividido em duas partes: na primeira, há uma breve apresentação dos principais elementos recorrentes nas representações do presente objeto de estudo; e na segunda, uma análise, com o aporte da história oral, das representações do espaço vivido de cinco moradores "nativos".

3. Ao utilizar neste trabalho os termos "nativo", "ilhéu", faz-se necessário esclarecer que não consideradas apenas as pessoas que nasceram na Ilha, mas também os imigrantes que nasceram em outras cidades e Estados e que fixaram uma moradia permanente em Itamaracá. Este enquadramento é justificado pelo fato de muitos imigrantes já terem filhos que nasceram no território insular, demonstrando o "amplo espectro do termo nativo" (Fantin, 2000).

\section{Representando o Objeto de Estudo}

Localizada ao norte, cerca de 50 quilômetros da cidade do Recife, a Ilha de Itamaracá é ligada ao continente através da ponte Getúlio Vargas (375 metros). Município integrante da Região Metropolitana do Recife (RMR), a Ilha de Itamaracá tem 65,4 quilômetros quadrados de extensão, representando 0,07\% do território pernambucano. Sua porção leste é banhada pelo Oceano Atlântico, enquanto o Canal de Santa Cruz, braço de mar de 22 quilômetros de extensão aproximada e com uma área estuarina de cerca de 5.292 hectares, banha o norte, o oeste e o sul da ilha.

Segundo o Censo Demográfico 2000, a população de Itamaracá é de 15.854 habitantes, estando 12.930 na zona urbana e 2.924 na zona rural. Apesar de ter a segunda menor população da RMR, durante o período de alta estação (de setembro a março), que contempla as férias escolares, a população flutuante da Ilha chega, aproximadamente, a 50 mil habitantes, ocasionando uma sobrecarga da infra-estrutura existente, que já é deficiente em relação à demanda básica.

A Ilha de Itamaracá se configura, no contexto metropolitano, como uma "zona periférica de lazer" que atrai os fluxos polarizados da área central (Recife) e das suas adjacências. Sua singularidade insular e a proximidade do núcleo metropolitano tornaram-na um destino privilegiado para os mais diferentes tipos e classes sociais, que se vinculam ao turismo de segunda residência ${ }^{4}$ e ao pendular comercial, assim como ao "turismo" de massa, dos excursionistas de finais de semana, pejorativamente conhecidos como "farofeiros".

"Ilha da Ciranda", "Ilha do Amor", "Ilha da Fantasia" são alguns dos slogans atribuídos a Itamaracá para comercializar suas paisagens. $O$ turismo que se baseava, principalmente, na venda de terrenos para segundas residências, tinha nas músicas de Lia da Ciranda e Reginaldo Rossi seus principais ícones de divulgação.

Maria Madalena Correia do Nascimento, popularmente conhecida como Lia da Ciranda, é a filha mais ilustre de Itamaracá, e quem até hoje divulga, com sua música, a Ilha para o Brasil e para o mundo.

Estava na beira da praia ouvindo as pancadas das ondas do mar. Esta ciranda quem me deu foi Lia, que mora na Ilha de Itamaracá [...]

4. Segunda residência ou residência secundária "é um alojamento turístico particular, utilizado temporariamente, nos momentos de lazer, por pessoas que têm seu domicílio permanente num outro lugar" (Tulik, 1995). 
Estes versos antológicos cantados por Lia desde a década de 1960 integram as principais representaçōes aludidas pelos turistas que visitam Itamaracá ou que têm interesse em conhecê-la. Desde a década de 1970, quando começou a divulgar sua ciranda, Lia é a maior fomentadora da cultura da Ilha. "Nas minhas viagens, digo que Itamaracá é encantada. Eu saio para divulgar minha cultura, mas sempre volto", afirma Lia em entrevista. Apesar da sua importância, ela se ressente da falta de apoio para uma maior divulgação do seu trabalho e da Ilha.

O cantor Reginaldo Rossi, um antigo turista de segunda residência, também contribuiu bastante para divulgar as belezas naturais da Ilha e vender suas paisagens por meio de músicas como:

Itamaracá - Pedra que Canta (1985)

Itamaracá é uma ilha encantada, lugar mais bonito que eu vi. Itamaracá é um reino encantado e todos são reis por aqui. Ilha de sonho, de luz e de cor. Terra que canta o amor. Essa areia tão branca, teu céu e o teu mar, paraíso é Itamaracá $[\ldots]$

\section{Férias em Itamaracá (1989)}

Pegue sua gata e seu carro e vá passar alguns dias em Itamaracá. Se for mulher, pegue um gato, uma viseira e um sapato e vá curtir muito sol... Se você quer a felicidade que na cidade grande não há, pegue seus panos de bunda e vá passar alguns dias em Itamaracá $[. .$.

Os simulacros paradisíacos da Ilha são sublimados nestas músicas. Os turistas eram convidados a conhecer o "reino da fantasia" e a desfrutar das suas paisagens naturais. Estas músicas foram lançadas no período áureo das segundas residências em Itamaracá e contribuíram para consolidar a imagem da Ilha como um dos principais destinos turísticos da população metropolitana. Em entrevista a um jornal local, em 1999, Reginaldo Rossi declarava: "Há muito tempo que Itamaracá me inspira, uma ilha junto da capital; toda ilha tem um misticismo, é gostosa de se freqüentar e eu sempre sonhei fazer de Itamaracá o Havaí. Como o Havaí está para os Estados Unidos, Itamaracá estaria para o Brasil’".

Contudo, como muitas ilhas brasileiras, as representaçōes de Itamaracá também são marcadas pelos opostos: de um lado a idéia de "ilha-paraíso"; do outro a de "ilha-prisão", que convive com três penitenciárias instaladas pelo Estado (a Professor Barreto Campelo - de segurança máxima -, a Penitenciária Agrícola de Itamaracá - PAI, de regime semi-aberto - e o Manicômio Judiciário).

A existência dessas três penitenciárias representa um período do planejamento em que a idéia de ilha, conforme sugere sua tradução para o italiano isola, estava associada à idéia de prisão, de isolamento (Diegues, 1998). Porém, o crescimento do turismo aliado a outros fatores conjunturais como violência, desemprego, etc., tem desencadeado diversos processos de tentativas de expulsão e retirada das penitenciárias de Itamaracá.

Nas últimas três décadas, a venda de terrenos para as segundas residências foi o principal produto turístico de Itamaracá. A especulação imobiliária ditou o parcelamento do solo para a abertura dos loteamentos, resultando numa alta densidade de ocupação do espaço litorâneo. No Censo 2000, o IBGE contabilizou 7.385 domicílios de uso ocasional (segundas residências) que representavam cerca de $60 \%$ do total dos 12.366 domicílios recenseados. Estes domićlios de segunda residência apresentaram uma taxa geométrica de crescimento anual de $8,97 \%$ de 1970 a 1980, de $12 \%$ de 1980 a 1991 , e de 5,18\% de 1991 a 2000, registrando, neste último período, uma queda no ritmo de crescimento e em relação ao total de domicílios da Ilha.

Os impactos ambientais ocasionados aos estuários, mangues, praias, restingas e matas de Itamaracá aparentam estar diretamente atrelados à expansão dos empreendimentos turísticos, principalmente das residências secundárias. A capitalização desenfreada do litoral para a construção desses alojamentos tem gerado a expansão da urbanização e dos moradores adventícios ${ }^{5}$, a degradação da paisagem natural e o arrefecimento da própria atividade turística. Isto, conseqüentemente, também ocasiona a perda da sustentabilidade da população "nativa", pois grande parte dela tem seus empregos atrelados ao turismo (Assis, 2001).

A mudança de uma paisagem agropesqueira para uma paisagem dominada pelo uso da segunda residência acarretou para a população itamaracaense, por um lado, o aumento e a diversificação da oferta de trabalho (com o aparecimento de novas atividades) e a melhoria da infra-estrutura urbana (com a ampliação do comércio e a maior oferta de equipamentos e serviços públicos); por outro lado, esta transição também ocasionou o decréscimo de atividades tradicionais (como a agricultura e a pesca), a marginalização de parcela da população desqualificada que não conseguiu se engajar nas novas atividades impostas pelo turismo, o surgimento de novos estilos de vida e padrōes de consumo que culminaram com a progressiva destruição das tradições e crenças locais.

5. São considerados moradores adventícios os antigos turistas que transformam suas residências secundárias em residências permanentes, transferindo seu domicílio principal para os núcleos receptores. 
Poemas, mapas, fotografias, músicas, crônicas, reportagens, entre outros indicadores, consubstanciam a amplitude de meios de captação das representações da difusão do turismo no espaço vivido dos "nativos". Nesse sentido, Gomes (1997) também sinaliza algumas pistas metodológicas, assinalando que, "ao lado da literatura, os registros iconográficos constituem-se em pressupostos indispensáveis à recuperação da exegese da cidade e de seus microespaços, numa perspectiva da sua evolução".

Apesar desse estudo também utilizar alguns desses procedimentos, dar-se-á maior enfoque às representações emanadas dos depoimentos de cinco "nativos" da Ilha de Itamaracá. Pelo caráter exploratório deste ensaio, a seleção dessa amostra é apenas um indicativo da problemática apresentada, não esgotando a discussão e a necessidade de estudos mais acurados.

\section{Representando o Espaço Vivido pelas Falas dos Moradores}

A análise de depoimentos orais é apenas mais uma forma de representação do espaço vivido. Como todos os métodos científicos, a história oral também apresenta as suas limitações e dificuldadcs. Ressalta-sc, porém, que pelo escopo deste trabalho não se procura seguir detidamente os procedimentos que este método de investigação prescreve. Busca-se na história oral, sobretudo, orientações de como conduzir as entrevistas para que os teores das respostas permitam captar as representações do espaço vivido dos entrevistados.

No bojo dos relatos de experiências pessoais, destacaram-se recordações, nostalgia, sentimentos de perdas e ganhos, de felicidades e tristezas, que muitas vezes contradizem os depoimentos, mas que seguem a pluralidade dos modos de pensamento contemporâneos constatados por Moscovici (1978). Isto também serve de alerta para que haja cautela na análise de apenas uma das muitas facetas do turismo - a sua incidência no espaço vivido.

Assim, seguindo o rumo dos depoimentos, não há uma preocupação em obedecer a uma linearidade histórica. Seguir-se-á a trilha da memória dos entrevistados com o intuito de resgatar as marcas, sentimentos e experiências as mais variadas que darão subsídios para a (re)construção do espaço vivido da Ilha de Itamaracá.

As cinco pessoas entrevistadas foram os senhores Nilton (75 anos) e Pedro (83); e as senhoras Maria (70), Severina (72) e Celina (75). Todos são aposentados e residem em Itamaracá desde que nasceram. Nos seus depoimentos, as representações do espaço vivido relatadas sempre estiveram associadas a alguns marcos históricos como "antes e depois da construção da ponte"; "antes e depois da energia elétrica"; “antes e depois da emancipação", etc. Essas recordações e experiências do antes e do depois expõem as marcas que a atividade turística engendrou no imaginário da população "nativa", revelando a "experiência da perda da cidade" (Fantin, 2000). Nesse âmbito, os depoimentos orais apresentam "duas Itamaracás": a de antes, que era dos "nativos"; e a de depois (atual), que é dos turistas.

$\mathrm{Na}$ "Itamaracá de antes da ponte" as principais atividades econômicas eram a pesca, as barcaças ${ }^{6}$, a colheita de coco e a produção do sal. A população, na sua maioria, era formada por pescadores que moravam em caiçaras ${ }^{7}$ nas praias. Conforme relatam os entrevistados:

Por aqui tudo era mato; a maioria era casa de palha [folha de coqueiro]; tudo era mocambo. Tudo era carregado nas barcaças; era coco, era carvão, tudo o que entrava e que saía. Ninguém vinha visitar a ilha nem o Forte [Orange] porque tudo tinha medo da maré. (Pedro)

A vida das mulheres da ilha era consertar peixe, lavar, passar e costurar roupa. A vida dos homens era salina, coqueiro e maré. Outros homens trabalhavam de barcaça no transporte de mantimento e de tudo. Aquele tempo era bom as festas; agora de fome, aquele era o tempo de fome. $O$ povo passava muitafome, mas não morria disso não. Se plantava, ia buscar na maré.(Nilton)

Os depoimentos desta Itamaracá de "antes da ponte", de "antes da energia elétrica", exaltam as manifestações culturais desse período como momentos de "celebrações do mundo da vida". Apesar das dificuldades socioeconômicas, as festas eram alegres, animadas, e tinham a participação de todos os moradores.

As festa daquele tempo era muito boa. Tinha pastoril, caboclinho, cavalomarinho, fandango, ciranda [...] muita brincadeira. [...] As brincadeiras eram muito animada. Mas o melhor de tudo era o fandango e o pastoril. Estes era muito falados e tinha gente que vinha de longe ver as brincadeiras. (Severina)

Pras festas se trazia carrossel, mulher da vida, tudo nas barcaças. Nas festas se tinha fandango, pastoril, bumba-meu-boi.Se trazia as bandas de música também.(Pedro)

6. Espécies de pequenas balsas que faziam o transporte marítimo de mantimentos e de pessoas. Até a década de 1930, era o único meio de comunicação da Ilha com a capital (Recife) e outras cidades do litoral nordestino. Em meados da década de 1950, elas desapareceram com a abertura das estradas e a chegada do automóvel, do caminhão.

7. Este termo, em Itamaracá, é usado mais especificamente com referência às palhoças - "as caiçaras" - construídas nas praias onde muitos pescadores residiam e guardavam as suas embarcaçoes; diferente do sentido mais genérico - "os caiçaras" - atribuído aos pescadores que habitam as áreas costeiras dos Estados do Rio de Janeiro, São Paulo, Paraná e norte de Santa Catarina. 
Nessa época, entre 1940 e 1960, de todas as atraçōes o fandango era a mais popular, até mesmo do que a ciranda. Segundo Cézar (1989), “o fandango é uma dança de origem espanhola ou ibérica para sermos mais abrangentes. (...) No Nordeste o fandango assume a sua brasilidade, embora ainda muito lusitana. Misturando as danças ternárias com binários sincopados dos 'cocos de praia', os velhos romances europeus, mesclados de feitos heróicos de cavaleiros medievais, e histórias de navegantes portugueses num caldeirão de culturas, fervido e mexido ao sol das praias nordestinas, o fandango nasceu como auto, pleno de teatralidade, rico de lindas melodias e como é comum às manifestaçōes do povo, com forte teor religioso. (...) O fandango da Ilha de Itamaracá é um dos mais antigos da região litorânea do Nordeste ou quiçá o mais antigo".

O fandango era formado por um grupo de rapazes, geralmente embarcadiços ou marítimos, alguns ligados ao comércio ou à pesca. [...] Os ensaios começavam no mês de maio, à luz dos candeeiros, isto por volta de 1920; os rapazes alugavam uma casa para ensaiar e todos colaboravam para pagar o aluguel (Cézar, 1989). A última apresentação do fandango de Itamaracá foi em 1972. Posteriormente, a ciranda se popularizou na voz da cantora Lia e serviu para a divulgação da Ilha de Itamaracá mundialmente.

Após a construção da ponte Getúlio Vargas e da emancipação da Ilha, as atividades turísticas em Itamaracá se intensificaram rapidamente. Como atestam os depoimentos, a chegada dos turistas provocou um choque cultural que resultou em transformaçōes no espaço vivido da população "nativa".

A chegada dos turista era no verão que vinha os veranista que alugava as casas dos moradores daqui; as casas melhores e as casas de palha também quando era casinha limpinha, bonitinha... aí foram comprando o terreno e fazendo casas. Depois já vinha o dia que quisesse, o mês que queria vir, que tava desocupado e lá vai a coisa crescendo... Foi se chegando o tempo de dizerem que tinha que vender a casa de palha dos pobres que tinha que recuar pra trás porque era obrigado a vender o lugar, as casas na frente pra fazerem casa nova e o povo foi tudo se arrastando pra trás fazendo as casinhas pra trás e depois lá chegou que nem casa de palha podia se ter que hoje em dia todo mundo tem casa de telha. ...Era difícil ter barulho [confusão], mas o lugar aumentou e passou pras outras pessoa e as pessoas velha anda por aí e procura com a vista uma pessoa que foi do lugar e dá trabalho achar porque tudo é gente de fora; ...Agora taí uma cidade que ninguém sabe, nem misericórdia, até a gente se perde. Se não tiver acostumado se perde porque todo canto é casa. (Celina)

Estes relatos evidenciam que o incremento voraz dos empreendimentos turísticos em Itamaracá foi, paulatinamente, periferizando as comunidades "nati- vas" de pescadores, as quais passaram a morar distante do mar, mudando seus gêneros de vida, seus hábitos e costumes. Segundo Carlos (1999), neste processo "[...] transforma-se constantemente o lugar e produz-se o estranhamento a partir de sua desfiguração debaixo do concreto armado".

O povo foi morar mais distante da praia porque o mar estava acabando as casas e o povo foi vendendo. O povo não tinha dinheiro pra consertar e os veranistas quando chegou só queria a praia. As casas todas da praia era de pescador, mas hoje ninguém mora lá. Não se tinha condiçōes de comprar os terrenos que era de invasão e o dinheiro da venda dava pra comprar outra casinha mais atrás e fazer outro negócio. (Nilton)

Os donos dos terrenos começaram a lotear e loteando os pobres não podiam comprar. Os donos dos terrenos chegava e perguntava se podia comprar o terreno e fazer a casa de telha porque agora era uma ordem que tinha e só podia morar na praia quem tivesse a casa de telha. Os pobres não podia comprar; se botasse telha a casa não agüentava; se fizesse a casa, o dinheiro da indenização não dava. O dono dos terrenos indenizava o povo, mas o dinheiro não dava pra construir a casa de telha. (Celina)

Estes depoimentos denunciam a transformação da paisagem-fetiche para a paisagem-mercadoria. Este processo, sob a ótica dos que o vivenciaram, demonstra a pressão imposta pelos agentes imobiliários aos moradores "nativos" na busca de lotear e vender os terrenos da beira-mar. A mudança do local de residência dos pescadores, das suas atividades, dos seus hábitos, “[...] estabelece o choque entre uso e troca; a propriedade privada invade o cotidiano e provoca o estranhamento do indivíduo instigado pelas mudanças nos usos e nos modos de uso de um espaço que se recria para o consumo dele próprio" (Carlos, 1999).

Na "Itamaracá de depois da ponte", a instalação das penitenciárias também incidiu nas representaçōes do espaço vivido dos moradores "nativos", pois muitos conviveram com o estigma de residir numa "ilha-prisão".

As penitenciárias sempre foi uma coisa muito ruim pra Itamaracá. Antigamente, quando eu dizia que morava em Itamaracá, o povo pensava que eu era preso, que todo mundo que morava em Itamaracá era do presídio. Hoje eu já estou mais acostumado. Era melhor transformar as penitenciárias num hospital, num colégio ou num orfanato. Itamaracá nunca devia ter penitenciária. (Nilton)

De acordo com a trajetória e as experiências vividas por cada entrevistado, as representaçōes do espaço vivido de Itamaracá (do antes e do depois do turis- 
mo) denotam percepções diferenciadas da vida cotidiana. Por isso, as representações que os entrevistados têm da difusão do turismo na Ilha só podem ser entendidas considerando as diversas histórias de vidas relatadas nas suas falas. Assim, compreender-se-á o porquê das contradições e das divergências de opiniões e tentar-se-á captar quais as representações que os entrevistados têm da "Itamaracá de depois..., da Itamaracá atual.

Pra mim o crescimento do turismo não foi nada de bom. Na minha opinião, não sei lá pros outro, no tempo velho era melhor pros pobre viver. (Pedro)

A chegada dos turistas protegeu muita gente porque o pessoal deixava renda pro povo daqui. Uma fazia doce, vendia caju e tinha emprego. Muita gente daqui está empregada por causa do povo de fora. Se esses veranistas todinho vender as casas pra sair daqui, acabou-se o emprego. Ainda tem muita gente daqui empregado por causa dos veranista. E tem muita gente de fora que vem trabalhar aqui, tomar conta de casa dos veranista aqui, mas mora no Recife; outros já tão morando aqui com a família. [...] Itamaracá melhorou muito e o povo também. [...] Os turistas tão saindo da ilha por má administração. Não foi culpa deles. Não tem mais brincadeiras então eles não vêm. (Nilton)

Depois que evoluiu apareceu trabalho pros pobre; nisso eu acho que foi melhor. Apareceu trabalho pro lugar que não tinha e mais nada. Mas de tudo quanto não presta apareceu um pedaço e ficou aqui. Tudo o quanto tem nos lugares grandes tem aqui também porque tem muita gente. Foi bom ter evoluído também porque agora tem hospital, tem farmácia; a gente não precisa ir pra Olinda de pé pra comprar um remédio como a gente fazia. [...] A culpa do lugar ter ficado ruim é dos veranista, de muita gente que veio e tomou conta do lugar e quer viver do jeito deles. Aonde se junta muito de tudo tem; gente boa e ruim. [...] Poucas são as pessoas daqui que conseguiu melhorar de vida. Eu corro a mente e não consigo encontrar ninguém. Pescador, trepador de coqueiro e salineiro se acabou. A prosperidade foi trabalhar de pedreiro e servente pra construir as casas dos veranista. [...] Hoje eles já tão vendendo muitas casa que tiveram gosto de fazer aqui. Tem muita casa de veranista com placa de vender. Tem muitos veranista que tem casa aqui e vão morar em outro canto. (Celina)

O crescimento do turismo foi positivo porque muita gente que tem uma casinha pra alugar hoje depende dos veranista. Muita gente que é empregado é por causa dos turistas porque eles deixa as casa e os moradores da ilha fica tomando conta, ganhando um dinheirinho. [...] Itamaracá tá ruim porque não tem festa, não tem brincadeira. O que eu sinto falta do meu lugar é a paz e as brincadeiras. O prefeito melhorando Itamaracá chama o povo para cá, chama os turista porque eles vê na televisão, no rádio e se aproxima tudo. [...] Com toda miséria, o lugar ainda é aqui; o lugar ainda é Itamaracá. (Severina)

Estes diferentes depoimentos que retratam a "Itamaracá de hoje" denotam que o turismo tem seus rebatimentos nas representações do espaço vivido dos "nativos". Mesclam-se nas suas representações opiniões dissonantes, favoráveis e contrárias ao processo desenhado pelo turismo na Ilha de Itamaracá. São aludidos os impactos positivos como a melhoria da infra-estrutura e a oferta de trabalho; e os impactos negativos, como a mudança dos gêneros de vida, dos costumes e tradições.

Diante disso, a relação custo-benefício torna-se difícil de ser avaliada. Porém, pela intensidade com que o turismo se difundiu nas paisagens insulares, os impactos negativos gerados acenam um porvir desalentador para grande parte da população "nativa" que hoje depende do turismo para sobreviver, pois, como remata a sra. Maria:

Naquele tempo a gente tinha peixe com fartura, tinha os coqueiros para caçar coco, tinha os trabalhos com enxada e agora nada disso tem mais [...]. Tudo foi se acabando depois dos turistas [...]. Mas, se eles tudo sair hoje, vai ser muito pior pro povo daqui.

O turismo, hoje, integra as representações dos "nativos" do espaço insular. Os "nativos" não se reconhecem mais habitando um espaço sui generis. O capital, encoberto pelo "manto mágico do turismo", (re)organiza o espaço insular, atribuindo-lhe novos usos e funções que assegurem a sua reprodução. A Ilha passa a ser uma extensão da metrópole, "re-encaixando-se" ao continente, (re)produzindo seus padrões sociais, estilos de vida e também seus problemas.

Estas metamorfoses do espaço vivido insular também são manifestas melancolicamente pelo ilhéu e escritor José Lopes no seu poema Itamaracá de Ontem (Lopes, 1987):

\section{Itamaracá:}

Cade os teus botes, que transportavam as feiras vindas de Itapissuma, para as tuas bodegas?

Onde estão os cavalos do velho Guilherme, que serviam de transporte aos nativos e veranistas?

Cadê teus engenhos bangüê, Amparo, São João e Macaxeira, onde se bebia caldo de cana, mel de engenho e mel de furo? 
Cadè o teu São João, onde as fogueiras queimavam em todas as ruas, fazendo um tapete de cinzas, onde todos pisavam para acompanhar a bandeira, dança o coco e tomar banho nos riachos, nas madrugadas, com toda a roupa do corpo? Que foi feito das tuas seculares salinas, onde se fazia sal de espuma? Onde estão as barcaças: Bomconselho, Utilidade, Beatriz, Sultana, Linda Flor, Berenice, Dirce e tantas outras que transportavam açúcar, coco, lenha e ficavam embandeiradas ancoradas no porto em dias de festa?

Cadè os teus pastoris, bumba-meu-boi, mamulengo, touradas, jagunços, fandangos?

Onde estão os teus tipos populares, Chico Velho da preguiça, Zé da Bomba, Caléu, Miguel Moreira, Etelvina?

Que foi feito dos candeeiros alcoviteiros que iluminavam as casas e a sua luz de carbureto que servia para iluminar os pastoris, os fandangos, mamulengos e bumba-meu-boi?

E os teus cajus, as castanhas assadas, a farinha de milho e os alfinins, que se vendiam nas ruas?

Onde estão os meninos que brincavam de banga e manja nas noites de lua, $e$ que faziam da flecha da cana braba o seu cavalo?

Que é feito dos namorados que passeavam na praia de braços dados ao luar? Cade teus guagirus, tuas célebres mangas jasmim (primavera) os muricis, as mangabas?

Tuas rendeiras que com obilro, alfinete e linha, faziam as rendas que ornamentavam os vestidos de noivas?

Cade a lenha e a casca de coco, onde no fogão de barro se preparavam muquecas gostosas?

Onde estão os ferros de engomar, aquecidos a carvão?

Cadé as jangadas de "pau de jangada", e o curral amarrado com cipó?

Onde estão os bules de bico de curvo, com os abafadores feitos de algodão, para não deixar o café esfriar?

E tuas escolas, com a carta de A B C, o craiom, a pedra negra, a caneta com o tinteiro e a palmatória?

Cade os bailes, onde os namorados se encontravam?

Que é feito das tuas noites Marianas (noites de noivas) tão animadas e freqüentadas por todos os jovens?

Onde estão os teus velhos, que calçavam tamancos, usavam chapéus de palha que fumavam cachimbo de madeira e cigarro enrolado colocado com o cuspo e que contavam estórias de trancoso, lobisomem e galafoice?

$E$ os teus quintais feitos de esteiras de varas e cangaços de palhas de coqueiros e as tuas ruas de areia quente?

Cadè os jumentos que pastavam nas ruas, as galinhas soltas que sempre deixavam ovos para se achar e ocanto dos galos anunciando na madrugada o alvorecer? Onde estão as tuas prostitutas (sem muito carinho, mas com muito medo do xeixo)?

Que é feito das benzedeiras de espinhela caída, mau olhado, cobreiro?
Cadè os botadores de água das aningas, da biquinha e do cazumbá?

Onde estão os vendedores de cuscuz, manguzá, bolo-de-rolo, alfinim e cocada?

$E$ os circos, com seus palhaços gritando pelas ruas: "Hoje tem espetáculo?”, e a criançada respondendo, "tem sim-senhor"?

Cadé os teus parreirais, que ornamentavam os quintais e davam ótimas uvas?

E teus carnavais, com lança-perfume, serpentinas e banho de cheiro?

Itamaracá, hoje estais descaracterizada, tudo acabou, o progresso levou

tudo, deixou apenas saudades.

Os amiúdes do espaço vivido insular evocados neste poema reforçam as representações da "Itamaracá de antes", aludida nos depoimentos dos cinco idosos "ilhéus".

\section{Considerações Finais}

As tentativas de representação do espaço vivido apresentadas nesta análise evocam a história oral como fonte de resgate da experiência cotidiana. Deixando que os depoimentos "falem" por sị sós, eles revelam as representaçōes socioespaciais concebidas por cinco "nativos" da Ilha de Itamaracá ao longo das últimas décadas.

Conscientes da inexorabilidade do tempo e da sucessão dos eventos que transformam e imprimem as marcas nas paisagens, estes relatos não têm a pretensão de rotulá-los como "a história única e verdadeira", nem de incentivar o "saudosismo" dos espaços vividos. Contudo, o conhecimento de mais esta versão (que é apenas mais uma visão de mundo) pode contribuir para o resgate da história de Itamaracá e para as atividades de planejamento turístico que muitas vezes desprezam estas representaçōes elencadas.

Ademais, as reflexões arroladas neste artigo, longe de terem um caráter conclusivo, deixam "pistas" para novas inquietaçōes sobre os aportes da Geografia para os estudos do Turismo.

\section{Referências Bibliográficas}

ASSIS, L. F. 2001. A difusão do turismo de segunda residência nas paisagens insulares: um estudo sobre o litoral sul da Ilha de Itamaracá - PE. 177 f. Dissertaçāo (Mestrado em Geografia) Centro de Filosofia e Ciências Humanas, UFPE, Recife.

CARLOS, A. F. A. 1999. O consumo do espaço. In:___ (Org.). Novos caminhos da Geografia. São Paulo: Contexto, p. 173-186. 
CÉZAR, C. A. 1989. O Fandango de Itamaracá. Monografia (Artes Cênicas) - Centro de Artes e Comunicação, UFPE, Recife.

DIEGUES, A. C. 1998. Ilhas e mares: simbolismo e imaginário. São Paulo: Hucitec.

FANTIN, M. 2000. Cidade dividida: dilemas e disputas simbólicas em Florianópolis. Florianópolis: Cidade Futura.

GOMES, E. T. A. 1997. Recortes de paisagens na cidade do Recife: uma abordagem geográfica. 300 f. Tese (Doutorado em Geografia) - Faculdade de Filosofia, Letras e Ciências Humanas, USP, São Paulo.

LOPES, J. 1987. Histórias e segredos de uma ilha. Recife: Fundarpe.

MOSCOVICI, S. 1978. A representação social da psicanálise. Rio de Janeiro: Zahar.

TULIK, O. 1995. Residências secundárias: presença, dimensão e expressividade do fenômeno no Estado de São Paulo. 154 f. Tese (Livre-Docência) - Escola de Comunicações e Artes, USP, São Paulo.

Recebido em 14/08/2002

Aprovado em 16/12/2002 